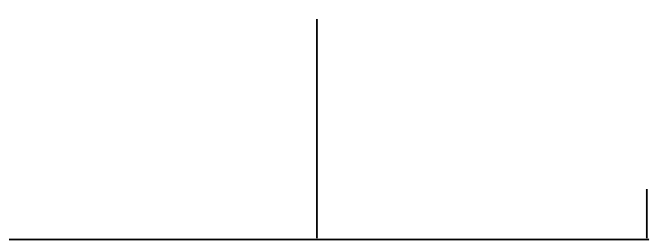

Rev. Latinoam. Psicopat. Fund., São Paulo, v. 13, n. 1, p. 71-86, março 2010

\title{
Para uma neurobiologia do eu: uma contribuição às teorias da subjetividade*
}

Sergio Gomes da Silva

\begin{abstract}
O objetivo do presente trabalho é analisar como a neurologia ou as neurociências tem proposto novas narrativas da mente a partir do ponto de vista biológico. $O$ autor aponta de forma crítica como essas disciplinas descrevem a vida subjetiva, a identidade pessoal e o nosso "eu” a partir das contribuições do neurologista António Damásio. Defende-se a idéia da necessidade de novas descrições subjetivas no campo clínico e nas teorias da mente tais como a psicologia e a psicanálise.
\end{abstract}

Palavras-chave: Subjetividade, eu, identidade, neurobiologia

* O referido artigo é uma versão modificada do terceiro capítulo da Dissertação de Mestrado em Saúde Coletiva: S. G. Silva, Imagens do corpo e imagens do eu: Ramachandran, Sacks e Damásio. 2007. Universidade Estadual do Rio de Janeiro. 


\section{Introdução}

A importância da biologia no mundo contemporâneo tem se configurado também no plano social e é uma consequência direta dos avanços tecnológicos. Sem os novos "instrumentos da vida", os neurocientistas e neurologistas não teriam condições de descrever o comportamento humano a partir das funções cerebrais vistas in loco por meio de modernos aparelhos de imageamento do cérebro. É como se pudéssemos, a partir dessa nova tecnologia, verificar como a mente funciona. Desde que Bichat exclamou "Abram-se os cadáveres!", que a tecnologia médica em torno do corpo buscou desvelar os segredos de sua interioridade, não parando mais de crescer e de refinar os mecanismos de busca desse pretenso segredo interior insofismável.

As discussões acerca da biologia dos sentimentos, das emoções, da identidade pessoal, da subjetividade humana e, acima de tudo, da identidade biológica, parecem não ter chegado a um fim, sobretudo do ponto de vista neurológico ou neurocientífico. Mas é preciso que se tenha em mente que cada cérebro, cada ínfima conexão de um neurônio com o outro, não é suficiente para identificar todos os seres humanos como sendo um só, dentro do ponto de vista daquilo que tem se configurado como o "sujeito cerebral". 
A ideia de um "sujeito cerebral" decorre, segundo Vidal (2005a, b) e Ehrenberg (2004), da concepção de personhood (personalidade, em inglês), ou seja, se por personalidade entendemos a qualidade ou condição de sermos uma pessoa, um indivíduo ou um sujeito com um sentido de ipseidade e um centro de gravidade narrativa, brainhood ou "sujeito cerebral" é a qualidade ou condição de "ser um cérebro" e é essa propriedade que define um sujeito. Por sua vez a figura do sujeito cerebral foi determinada pela influência galênica na psicologia do século XVIII e tem transformado o futuro das ciências médicas, a exemplo das neurociências e da neurologia na contemporaneidade.

Nesse sentido, o objetivo do presente trabalho, em um primeiro momento, é analisar como a neurologia e/ou as neurociências têm proposto novas narrativas da mente humana para, em seguida, apontar no aporte biológico as descrições da vida subjetiva, da identidade e do nosso "eu" a partir das contribuições de António Damásio.

\section{O sujeito cerebral, a experiência subjetiva e as novas narrativas da mente}

Cada cérebro é específico para cada ser humano, pois cada um apreende acerca de si mesmo e do mundo de modo individualizado. Mas conforme questiona Ehrenberg (2004), um dos autores que têm problematizado a figura do "sujeito cerebral" na contemporaneidade, a identidade biológica seria a identidade de uma pessoa considerada na sua totalidade? Seria o cérebro, o conjunto de conexões neuronais que nos individualiza, nos particulariza, nos torna únicos? Prescindimos de uma centelha divina em nossa demasiada escuridão visceral para compreendermos o ser humano, ou seria a mente, essa estranha personalidade "encarnada" na materialidade do nosso corpo, a grande responsável pelo sentido de ipseidade que tanto tentamos entender?

Quando biólogos, psicólogos cognitivistas, neurologistas e neurocientistas de várias ordens buscam provar que tudo o que nos particulariza diante do Outro e do mundo vem do interior, eles subestimam a nossa capacidade narrativa substituindo a materialidade metafísica por uma interioridade biológica.

O cérebro por si só não fala, não ouve, não tem a capacidade de discernir o que é um homem, uma casa ou uma montanha.

A experiência subjetiva, por sua vez, vai bem mais além. Para dar descrições de nós mesmos, não precisamos apenas de um cérebro, precisamos de uma men- 
te em condições de dar descrição de tudo o que ela apreende, pois, conforme reforça Bezerra Jr. (1999), a experiência subjetiva é encarnada, e dizer isto significa que a experiência subjetiva emerge e depende do funcionamento de um organismo complexo - o corpo humano - dotado de um recurso especial - o recurso à significação por meio da linguagem humana. A experiência subjetiva, ainda assim, também pode ser descrita como histórica, no sentido em que ela é fabricada de acordo com contextos sociais e culturais precisos por meio de descrições subjetivas.

Não negamos a visceralidade da carne do cérebro quando tomado a construir novas descrições do sujeito, muito menos desprezamos a necessidade de termos "um cérebro suficientemente bom" para poder apreender os estímulos vindos tanto do exterior quanto do interior do corpo. Afinal, a vida psíquica requer bem mais do que isso: requer uma interação entre o eu e o mundo, entre o corpo e o mundo, entre a mente e o mundo, entre o cérebro e mundo, sem o qual, não teríamos condições de dar descrições nem do mundo, nem de nós mesmos.

Para tanto, precisamos analisar as contribuições das ciências médicas, fisiológicas ou biológicas na compreensão da mente humana. Precisamos entender que a psicologia ou até mesmo a psicanálise podem usufruir de outras definições, descrições e caracterizações da nossa interioridade.

Erik Kandel é um bom exemplo disso. Ganhador do Prêmio Nobel de Fisiologia e Medicina em 2000, ele mostrou as contribuições da neurologia e das neurociências no campo das ciências psis, inclusive defendendo a psicanálise como ferramenta teórica da mente. Não obstante, Kandel é crítico quanto à relutância dos psicanalistas no que se refere a aproveitar as oportunidades que as ciências de um modo geral têm a oferecer ao campo da mente.

Na sua perspectiva, a psicanálise, tal como foi desenvolvida no século XX, foi prejudicada por uma concepção mais cientificista da mente, relegando para segundo plano os aportes das ciências biológicas, não obstante Freud ter feito uso das ideias de Darwin ao descrever em seu "Projeto para uma psicologia científica" uma concepção neurológica de mente.

Mas de acordo com Eric Kandel a biologia pode transformar a psicanálise em uma disciplina cientificamente mais fundamentada. Kandel $(1999 ; 2005)$ especifica oito áreas em que a biologia e a psicanálise poderiam cooperar: a natureza do inconsciente dos processos mentais; a natureza da causalidade psicológica; a causalidade psicológica e a psicopatologia; as primeiras experiências e a predisposição para as doenças mentais; o pré-consciente, o inconscien- 
te e o córtex pré-frontal; a orientação sexual; a psicoterapia e as mudanças estruturais no cérebro e, finalmente, a psicofarmacologia como um acessório à psicanálise. Todas elas não privilegiam a fisicalidade dos processos psíquicos, nem subestimam as descrições psicológicas e narrativas da mente, pelo contrário, tanto uma quanto a outra estão imbricadas. ${ }^{1}$

Para o autor, os estudos biológicos, neurológicos e neurocientíficos podem contribuir para aquilo que ele chama de uma "biologia da subjetividade, da consciência, da ipseidade e do conflito".

Até bem pouco tempo havia poucas maneiras independentes e convincentes de testar ideias psicodinâmicas ou avaliar a eficácia relativa de uma abordagem sobre outra. No entanto a neuroimagem pode nos fornecer justamente isso - um método de desvendar tanto a dinâmica mental quanto o funcionamento de um cérebro vivo. (...) De fato já podemos descrever o cérebro das pessoas antes e depois da terapia e desta forma ver as consequências da intervenção psicoterapêutica em certos transtornos. (Kandel, 2005, p. 386)

O que a neurologia atual pode trazer de contribuição para as teorias da mente, entre tantas, é apontar não só o referente corporal da nossa subjetividade como também descrever, de um modo fisicalista não dedutivo, como essa subjetividade está predisposta em nosso cérebro, pois, segundo Kandel, o cérebro não espelha o mundo como uma câmera, ele o decompõe em imagens e sensações para então reconstruí-lo na mente.

Conforme adverte Costa (2007), qualquer hipótese neural da experiência subjetiva deve ser capaz de explicá-la em termos da relação corpo-ambiente ou corpo-mundo. Para nos autorreferenciar precisamos dessa interação com o mundo ou com o ambiente, e quem possibilita ter a percepção de sermos um "ser indivisível", que temos uma ipseidade, que somos um "eu" com uma qualidade subjetiva, essa referência só nos é dada pelo Outro.

1. O próprio Kandel, em outro momento, afirmaria: “... a biologia pode revigorar a exploração psicanalítica da mente. Devo dizer, de saída, que embora esboçamos o que poderia evoluir para uma significativa fundamentação biológica para a psicanálise, estamos recém nos primórdios deste processo. Ainda não temos uma compreensão satisfatória dos complexos processos mentais. Mesmo assim, a biologia tem feito progressos notáveis nos últimos cinquenta anos, e os passos não estão diminuindo. Como os biólogos focalizaram seus esforços na compreensão do cérebro/mente, a maior parte deles está convencida de que a mente representará para a biologia do século XXI o que os genes representaram para a biologia do século XX" (Kandel, 1999, p. 508). 
O cérebro é um elo na cadeia que liga o corpo ao ambiente/mundo. Sua higidez, obviamente é uma condição necessária à gênese e ao equilíbrio das atividades mentais. Mas o mesmo poderia ser dito do restante da matéria corporal e do ambiente. O corpo do sujeito não é um apêndice diluído do cérebro, assim como o ambiente não é uma contração gramatical de estímulos atomizados por aparatos teóricos e instrumentais. Não conhecemos sujeitos nascidos de cérebros em cuba, assim como não conhecemos sujeitos com corpo e mundo, mas desprovidos de cérebro. Para o materialismo não redutivista ou naturalista pragmático, portanto, a identidade subjetiva não é uma fosforescência etérea emitida por redes e mapas neurais. (p. 20)

É provável que, em um futuro muito próximo, estejamos usando as ciências médicas, como a neurologia ou as neurociências, como aporte de nossas teorias mentalistas acerca da subjetividade e da identidade, construindo novas narrativas da mente.

A partir desse novo paradigma para as ciências médicas, novas teorias sobre a subjetividade humana foram surgindo, configurando-se naquilo que foi denominado de "as premissas do determinismo biológico da mente" ao se reconhecer os avanços das neurociências no modelo médico e na vida social, tais como as teorias da mente e da subjetividade humana pontuadas pelo neurologista e neurocientista António Damásio.

\section{Damásio e a descrição neurobiológica do self}

Muitos outros autores já descreveram biologicamente a subjetividade humana. Daniel Dennett foi um deles ao abordar a noção de "eu" ou self a partir da ruptura da subjetividade e do psiquismo com a natureza ou o organismo, inserindo-a na ordem dos processos biológicos. O "eu”, para Dennett, é um "eu biológico" influenciado pelas injunções do meio e diferenciando-se de outros "eus" por meio da própria evolução. Para esse autor, o "eu" é completamente desprovido de substância, é descentrado, clivado e sem essência, em um contínuo processo de autoengendramento (Dennett, 1986; 1991; 1997).

Muito próximo dessa definição encontra-se a noção de "eu" e "subjetividade" em Damásio. Ilustremos com dois casos estudados pelo autor.

O primeiro deles trata-se de Phineas Gage: um rapaz de 25 anos, morador de uma cidade na Nova Inglaterra que trabalha na Estrada de Ferro Ruttland \& 
Burlington assentando trilhos numa ferrovia em Vermont. É definido como um trabalhador eficiente e capaz pelos seus superiores. Sua tarefa consiste em explodir minas nas rochas para abrir caminho por onde passarão os trilhos. Para tanto, é preciso fazer buracos na rocha, enchê-los com pólvora até a metade, adicionar o rastilho e cobrir a pólvora com areia, que por sua vez é calcada com uma barra de ferro mediante algumas pancadas com o martelo, para posteriormente acender o rastilho e explodir a rocha com a pólvora. Gage é metódico, mas um descuido nessa tarefa faz com que ocorra um acidente sem precedentes. Antes de um ajudante colocar a areia sobre a pólvora, Gage martela a barra de ferro. Dá-se uma explosão diretamente no seu rosto. A barra de ferro, porém, entra pela face esquerda de Gage trespassando a base do crânio.

Gage, como se sabe, não morreu, mas após a remoção cirúrgica da barra de ferro, e depois de enfrentar uma dolorosa recuperação do acidente, "Gage deixou de ser Gage", transformando-se em um trabalhador irresponsável, não conseguindo manter-se mais em nenhum emprego, apresentando diversos desvios de comportamento, tendo a saúde deteriorada em 1859, vindo a falecer em 1861. Seu crânio foi estudado por diversos médicos neurologistas da época e seu caso entrou para a literatura como prova de que lesões cerebrais afetam não só o corpo, mas também a personalidade e o comportamento dos indivíduos.

Descrito como o Phineas Gage moderno, o segundo caso refere-se a Elliott. Elliott foi um paciente de António Damásio que chamou sua atenção em vista do diagnóstico médico que o encaminhou. $\mathrm{O}$ paciente havia sofrido uma alteração radical da personalidade e os médicos queriam saber se esse tipo de comportamento era, na verdade, alguma doença rara. Elliott, segundo Damásio, era um homem inteligente, competente e robusto que necessitava ser chamado à razão para voltar ao trabalho visto que ele apresentava comportamento "preguiçoso" apesar de suas capacidades mentais estarem inatas. Ele tinha conhecimento do mundo à sua volta, discutia assuntos políticos, conhecia a situação econômica e suas capacidades profissionais pareciam estar inalteradas. Era um bom pai e um bom marido até aquela ocasião, porém após o diagnóstico de um tumor cerebral seguido de uma cirurgia para a sua retirada, Elliott passou a exibir mudanças na sua personalidade. Era incapaz de se arrumar sozinho para o trabalho. Quando lá chegava, parava a todo instante, pois uma tarefa se ocupava de outra. Passou a desenvolver hábitos de colecionador e tinha dificuldade em tomar decisões próprias. Enfim, Elliott tornara-se o novo Phineas Gage, e isso serviu para, mais uma vez, provar que lesão em um dos hemisférios cerebrais era capaz não só de afe- 
tar a dinâmica do corpo - os movimentos, os sentidos ou a percepção destes -, mas também a personalidade ou a identidade do sujeito.

Damásio (1996) passa, então, a argumentar em favor de uma certa "biologia da mente e da subjetividade" ao afirmar que não é exagero postular a mente como resultante das interações entre o cérebro e o corpo em termos da biologia evolutiva, ontogenia e funcionamento atual.

O que estou sugerindo é que a mente surge da atividade nos circuitos neurais, sem sombra de dúvida, mas muitos desses circuitos são configurados durante a evolução por requisitos funcionais do organismo. Só poderá haver uma mente normal se esses circuitos contiverem representações básicas do organismo e se continuarem a monitorar os estados do organismo em ação. (...) Não estou afirmando que a mente se encontra no corpo. Mas que o corpo contribui para o cérebro com mais do que a manutenção da vida e com mais do que efeitos modulatórios. Contribui com um conteúdo [grifo do autor] essencial para o funcionamento da mente normal. (p. 257)

É a partir dessa argumentação que o autor vai discutir as bases neurais do "eu". Para Damásio (1996) o "eu" é um estado biológico constantemente reconstruído. Para ele, ter um "eu” está pautado na "unicidade do ser", ou seja, ter um "eu único" que nos particulariza e nos individualiza. Esta definição é perfeitamente compatível com a noção de Daniel Dennet de que não possuímos um "teatro cartesiano" em lugar do nosso cérebro, ou, dito de outro modo, o que Damásio postula é que há um "eu” para cada organismo exceto nas situações de doença mental, tais como nos casos de personalidade múltipla, ou ainda naqueles casos em que o "eu" foi diminuído ou foi eliminado, tais como nos casos de distúrbios da imagem corporal - anosognosia ou determinados tipos de epilepsia.

Mas, adverte ele, o "eu" que confere subjetividade à nossa experiência subjetiva não é um "impostor central” de tudo o que acontece nas nossas mentes, é necessário que diversos dispositivos corporais e cerebrais estejam em perfeita sincronia.

Para que o estado biológico do eu se verifique, é necessário que diversos sistemas cerebrais, bem como os inúmeros sistemas do corpo, estejam funcionando plenamente. Se você cortasse todos os nervos que levam sinais do cérebro para o corpo, seu estado do corpo alterar-se-ia radicalmente e, como consequência, o mesmo sucederia com sua mente. Se desligasse apenas os sinais do corpo para o cérebro, sua mente também se alteraria. Mesmo o bloqueio parcial do circuito cérebro-corpo, como sucede em doentes com lesões na medula espinhal, basta para ocasionar alterações do estado mental. (p. 258) 
Ao afirmar que o "eu" ou o self é, em síntese, biológico e fomentado por disposições neurais através do córtex cerebral, Damásio defende a ideia de que esse "eu" é continuamente ativado por dois conjuntos de representações: as representações de acontecimentos-chave na autobiografia do indivíduo, no qual é possível reconstituir a noção de identidade a partir da ativação parcial de mapas sensoriais dotados de organizações topográficas, e as representações primordiais do corpo do indivíduo - peça-chave para a construção da imagem do corpo e para a noção de "eu" e da nossa "subjetividade". Sempre que nos reportamos ao self nós nos reportamos à ideia de identidade e ao conjunto de características que definem um indivíduo. ${ }^{2}$

As primeiras representações formam um tipo de self o qual Damásio denominou de "self autobiográfico" (ou "eu autobiográfico", se quiserem). Esse tipo de representação dispositiva que descreve nossa autobiografia envolve um conjunto de fatos que definem uma pessoa - o que fazemos, do que e de quem gostamos, quais tipos de objetos usamos, que locais costumamos frequentar, que tipo de interação temos com o ambiente que nos rodeia, onde moramos e com quem trabalhamos, quem somos e quem são nossos amigos, quais seus nomes e nomes de parentes próximos e distantes etc. O "self autobiográfico", portanto, depende das lembranças sistematizadas de situações que ocorrem durante o processo de vigília ao longo de toda a vida de um indivíduo, gerando aquilo que Damásio (1996; 2000a) denominou de "memória autobiográfica".

O segundo tipo de representações forma um outro tipo de self, o chamado "self central". Nesse tipo de representação dispositiva está incluído a "memória do próprio corpo", ou seja, tudo aquilo que o corpo foi e tem sido na sua relação com o conjunto de interação entre ele e o ambiente interno e externo. De acordo com Damásio, a subjetividade depende, em grande parte, das alterações que têm lugar no estado do corpo durante e após o processamento de um determinado objeto, e abrange aquilo que ele denomina de sentimentos de fundo do corpo

2. De um modo geral, a palavra self é usada como sinônimo de "eu" tanto na fenomenologia como na psicanálise ou ainda nas neurociências. Em todos os casos, ressalta-se a importância do corpo (físico e mental) na constituição de nossa identidade. Há, portanto, diversos tipos de selves ou "eus": o "self biológico", o "self ecológico", o "self neurológico", o "self cerebral", o "self consciente", o "eu-pele", entre outros. Para um conhecimento ampliado dos diversos usos e sinônimos da palavra, remeto o leitor àqueles de maior relevo teórico, a exemplo de Anzieu (1989); Dennett (1986), Bermúdez et al. (1998); Campbell (1998); Butterworthy (1998). 
e os sentimentos emocionais. $\mathrm{O}$ autor ainda complementa: a representação coletiva do corpo constitui a base para o conceito de "eu" ou self. Tanto na evolução da espécie como no desenvolvimento do próprio sujeito, os sinais iniciais do corpo ajudam a construir um conceito de self ("eu") e é a referência de tudo o que pode acontecer ao organismo. Dito de outro modo, a cada instante, o estado do self é construído a partir da base (Damásio, 1996).

Os dois tipos de self assim constituídos correspondem a dois tipos de consciência: a "consciência central" e a "consciência autobiográfica".

A "consciência central" dá ao organismo um self referente ao momento e um lugar (agora e aqui). Ela não projeta o futuro, pelo contrário, ela nos dá a percepção de tudo o que ocorreu há poucos instantes. Como diz Damásio (2000a), “... não há outro lugar, não há antes, não há depois" (p. 34). A "consciência central" é um fenômeno biológico que possui apenas um nível de organização e depende da memória convencional, da memória operacional, do raciocínio e da linguagem.

A "consciência autobiográfica" ou ainda "consciência ampliada" possui níveis e graus diferentes e dá ao organismo um sentido de self, ou seja, uma identidade, uma personalidade, uma característica que individualiza uma pessoa. Ela é um fenômeno biológico complexo e conta com vários níveis de organização evoluindo no decorrer do organismo. Dito isto, ela depende da memória convencional e operacional cujo ápice é intensificado pela linguagem.

Só agora podemos verificar o apoio que Damásio (2000a) dá ao atributo da linguagem na construção da nossa subjetividade, ou seja, a partir dos dois níveis de consciência tal como ele as descreve. Desse modo, podemos afirmar que cada tipo de consciência corresponde a dois tipos de self:

O sentido do self que emerge na consciência central é o self central, uma entidade transitória, incessantemente recriada para cada objeto com o qual o cérebro interage. Nossa noção tradicional de self, porém, está ligada à ideia de identidade, e corresponde a um conjunto não transitório de fatos e modos de sermos únicos que caracterizam uma pessoa. A expressão que emprego para designar essa entidade é self autobiográfico. O self autobiográfico depende de lembranças sistematizadas de situações em que a consciência central participou do processo de conhecer as características mais invariáveis da vida de um organismo: quem o gerou, onde, quando, seus gostos e aversões, o modo como habitualmente se reage a um problema ou conflito, seu nome etc. Uso a expressão memória autobiográfica para denotar o registro organizado dos principais aspectos da biografia de um organismo. (p. 35) 
Mas ainda há de se registrar um lugar no cérebro, um dispositivo neural mínimo que possa produzir subjetividade. Damásio (1999) o localiza nos córtices sensoriais iniciais (incluindo os córtices somatossensoriais), regiões de associação cortical sensorial e motora e núcleo subcortical (especificamente a região do tálamo e gânglios basais) (p. 238).

Esse mecanismo neural não necessita de linguagem, ele corresponde àquilo que o autor denomina de "metaeu", ou seja, uma entidade que opera por meio dos esquemas cerebrais produtores da subjetividade.

A produção da subjetividade corresponde, assim, à produção de imagens de um objeto, às imagens das respostas do organismo ao objeto e, finalmente, a um terceiro tipo, qual seja, "a produção de imagens do organismo no ato de perceber e responder a um objeto" sem o acesso à linguagem e a narrativas diversas, visto que os humanos possuem a capacidade de experimentar uma emoção sem, no entanto, colocá-la em palavras por meio dos instrumentos representacionais do sistema sensorial e motor (Damásio, 1999, p. 237). O choro, o riso, o rubor, o susto, entre outros, são formas de esboçar uma emoção sem expô-la através de palavras.

Damásio também tece inúmeras considerações sobre a importância e o papel da pele na regulação e coordenação das representações do mundo exterior, visto que a pele é uma membrana e um órgão sensorial voltado para o exterior e preparado para construir a forma, a superfície, a textura e a temperatura dos objetos externos pelo sentido do tato. Ela também é responsável pela regulação homeostática do organismo, é controlada por sinais neurais autômatos do cérebro além de informações químicas vindas de diversos setores deste.

A representação da pele, para o autor, é um meio natural de estabelecer uma fronteira entre a interioridade e a exterioridade do corpo (a imagem corporal), porque ela está voltada tanto para o interior do próprio organismo quanto para o meio ambiente em que ele reage. A interação entre o organismo e o meio se daria, portanto, por meio de mapas sensoriais evidenciados, sobretudo, mas não apenas, pelo papel da pele (Damásio, 1996, p. 261). Damásio, assim, está frontalmente próximo das considerações das teses psicanalíticas de Anzieu (1989), ao ressaltar a importância da pele na construção de um "eu" como sendo um "eu pele", ou seja, uma estrutura psíquica a qual nossa subjetividade se exteriorizaria através do nosso "envelope corpóreo". O "eu-pele" é, acima de tudo, uma estrutura intermediária do aparelho psíquico entre a mãe e o bebê, uma membrana limitante e necessária para que seja equacionada a posição entre o "eu" e o "não eu". 
Em síntese, todos os seres humanos possuem uma capacidade de experienciar uma emoção sem, no entanto, colocar essa experiência sob forma narrativa, pois elas precedem o nível verbal. Essa "capacidade narrativa de primeira ordem" seria responsável pela produção de imagens cerebrais complexas, desde um simples objeto às imagens das respostas do organismo ao objeto. Já a "capacidade narrativa de segunda ordem" está a serviço da linguagem e produz relatos verbais a partir dos relatos não verbais. As narrativas de segunda ordem, segundo Damásio (1999), são aquelas responsáveis pela subjetividade humana.

Para Damásio, ora buscando apoio em referências filosóficas, ora buscando referências por meio das investigações dos distúrbios neurológicos de seus pacientes, o fizeram buscar na biologia das emoções e dos sentimentos as bases para a construção de um "eu" e de uma identidade, transformando o cérebro no grande ator em cena nesse imenso palco que é o "teatro do corpo" e o "teatro cartesiano das emoções e dos sentimentos".

O que as teorias de Damásio nos possibilitam é encontrar uma nova descrição da subjetividade humana, baseada principalmente na interação entre o mundo externo e o mundo interno, entre as áreas somatossensitivas do córtex cerebral e a mente, dando-nos descrições da subjetividade humana através da quebra dicotômica do pensamento cartesiano, pois, para o autor, não há separação entre o corpo, o mundo, a mente e o cérebro. Pelo contrário.

Como diz Andrieu (2000), o cérebro não é a condição do corpo, nem o corpo é a condição do cérebro, ou seja, não existe entre ambos uma ligação de causa e efeito, pois corpo e cérebro (e eu ainda acrescentaria - a mente) são indissociáveis e imprescindíveis. Não existe um sem o outro. Não existe mente sem corpo; muito menos mente sem cérebro: a mente é o resultado da interação entre eles. Até pode haver um corpo sem cérebro e sem mente, mas aí já não estamos mais no campo da subjetividade, da identidade, da personalidade, da interação entre o "eu" e o mundo exterior e o mundo interior, pois a vida subjetiva necessita de um cérebro, e um cérebro requer uma mente que, por sua vez, requer um corpo. "Essa neurobiologia do desenvolvimento recusa considerar a consciência corporal como o único resultado da atividade cerebral. A consciência corporal resulta dessa construção, tornada possível pela plasticidade do cérebro, e produzida pelas interações com o mundo" (p. 52).

Damásio conclui que os fenômenos mentais resultam da interação entre as atividades dos neurônios com o meio externo, o mundo exterior, o ambiente e o meio interno por intermédio daquilo que chamaríamos de uma "mente suficientemente boa". 
A "mente suficientemente boa" de Damásio está subsumida às capacidades perceptivas do cérebro de um indivíduo com o meio em que ele vive. Mais do que isso, a "mente suficientemente boa" de Damásio é aquela que dá ao cérebro toda a sorte de recursos e dispositivos neuronais e cerebrais do qual ele precisa para "situá-lo no mundo" ou no seu "campo de vida", ou ainda, dito de outro modo, é aquela que dá ao sujeito e ao seu cérebro os recursos e dispositivos necessários para a percepção dos objetos externos, do ambiente, de si, do seu próprio corpo e do corpo do outro.

Sem esse tipo de mente, não haveria cérebro, e, sem um cérebro, não haveria nem corpo, nem subjetividade. Damásio, portanto, funde três instâncias (mente, corpo e subjetividade) em uma única: o cérebro.

\section{Referências}

ANDRIEU, B. Lê cerveau: essai sur le corps pensant. Paris: Hatier, 2000.

Anzieu, D. O Eu-pele. São Paulo: Casa do Psicólogo, 1989.

Bergson, H. (1939). Matéria e memória: ensaio sobre a relação do corpo com o espírito. São Paulo: Martins Fontes, 1990.

BERMUDEZ, J.L. et al. Self-counsciousness and the body: na interdiciplinary introduction. In: BeRmudez, J.L. et al. (Eds.). The body and the self. Cambridge/ Massachusetts: The Massachusetts Institute of Techonology Press, 1998. p. 1-28.

BezerRa JR., B. Narratividade e construção da experiência subjetiva. In: Marzagão, L. R. et al. (Orgs.). Psicanálise e universidade: temas conexos. Belo Horizonte: Passos, 1999, p. 35-52.

. Naturalismo como antirreducionismo: notas sobre cérebro, mente e subjetividade. Cadernos do IPUB, Rio de Janeiro, v. VI, n. 18, p. 158-177, 2000.

Butterworth, G. An ecological perspective on the origins of self. In: Bermudez, J. L. et al. (Eds.). The Body and the Self. Cambridge/Massachusetts: The Massachusetts Institute of Techonology Press, 1998. p. 87-105.

Campbell, J. The body image and self-counsciouness In: Bermudez, J.L. et al. (Eds.). The Body and the Self. Cambridge/Massachusetts: The Massachusetts Institute of Techonology Press, 1998. p. 29-42.

Costa, J.F. O vestígio e a aura: corpo e consumismo na moral do espetáculo. Rio de Janeiro: Garamond, 2004. 
A psicanálise e o sujeito cerebral. In: $O$ risco de cada um. Rio de Janeiro: Garamond, 2007.

Damásio, A. O erro de Descartes: emoção, razão e cérebro humano. São Paulo: Companhia das Letras, 1996.

. O mistério da consciência: do corpo e das emoções ao conhecimento de si. São Paulo: Companhia das Letras, 2000a.

Dennett, D.C. The self as a center of narrative gravity. In: Kessel, F et al. (Eds.). Self and Counsciouness: Multiple Perspectives. New Jersey: Hillsdale, 1986.

. Consciouness Explained. Boston: Little Brown and Company, 1991.

. Tipos de mentes: rumo a uma compreensão da consciência. Rio de Janeiro:

Rocco, 1997.

EHRENBERG, A. Le sujet cerebral. Esprit, Paris, n. 309, p. 130-155, nov. 2004.

KANDEL, E.R. Biology and the future of psychoanalysis: a new intellectual framework for psychiatry revisited. American Journal of Psychiatric, n. 156, p. 505-524, Abr. 1999.

. Psychiatry, psychoanalysis and the new biology of mind. Washington (DC): American Psychiatric Publishing Inc, 2005.

VIDAL, F. Le sujet cerebral: une esquisse historique et conceptuelle. Psychiatrie, sciences humaines, neurosciences, v. 111, n. 11, p. 37-48, jan-frév. 2005a.

. Brainhood. In: Fischer, K. et al. (Eds.). Mind, Brain and Education. New York: Cambridge University Press, 2005b.

\section{Resumos}

(Para una neurobiología del yo: una contribución a las teorías de la subjetividad)

El objetivo de este estudio es analizar como la neurología o la neurociencia ha propuesto nuevas narrativas de la mente a partir del punto de vista biológico. El autor señala de forma crítica cómo esas disciplinas describen la vida subjetiva, la identidad personal y de nuestro yo a partir de las contribuciones del neurólogo Antonio Damasio. El autor defiende la idea de la necesidad de seguir las descripciones subjetivas en la clínica y la teoría de la mente, tales como la psicología y el psicoanálisis.

Palabras claves: La subjetividad, yo, identidad, neurobiología 
(Pour une neurobiologie du "moi": une contribution aux théories de la subjectivité)

L'objectif de cette étude est d'analyser de quelle façon la neurologie ou les neurosciences suggèrent de nouveaux récits de l'esprit du point de vue biologique. L'auteur décrit de façon critique comment ces disciplines décrivent la vie subjective, l'identité personnelle et notre "moi" à partir de la contribution du neurologue Antonio Damasio. L'auteur soutient l'idée de la nécessité de nouvelles descriptions subjective dans les domaines de la clinique et de la théorie de l'esprit, telles que la psychologie et la psychanalyse.

Mot clés: Subjectivité, moi, identité, neurobiologie

(For a neurobiology of the "self": a contribution to theories of subjectivity)

The objective of this study is to analyze how neurology and the neurosciences in general have theorized new narratives of the mind from the biological point of view. The author critically points out how these fields describe subjective life, personal identity and the "self", based on the approach of Antonio Damasio. Stress is given to the position that there is need for new descriptions of the subject in the clinical field and in theories of the mind, such as in psychology and psychoanalysis.

Key words: Subjectivity, self, identity, neurobiology

Citação/Citation: Silva, S.G. Para uma neurobiología do "eu": uma contribuição às teorías da subjetividade. Revista Latinoamericana de Psicopatologia Fundamental, São Paulo, v. 13, n.1, p. 71-86, mar. 2010.

Editor do artigo/Editor: Prof. Dr. Manoel Tosta Berlinck

Recebido/Received: $13.2 .2009 / 2.13 .2009$

Aceito/Accepted: $25.12 .2009 / 12.25 .2009$

Copyright: (C) 2010 Associação Universitária de Pesquisa em Psicopatologia Fundamental/University Association for Research in Fundamental Psychopathology. Este é um artigo de livre acesso, que permite uso irrestrito, distribuição re reprodução em qualquer meio, desde que o autor e a fonte sejam citados/ This is an open-acess article, which permits unrestricted use, distribution, and reproduction in any madium, provided the original author and source are credited

Financiamento: O autor declara não ter sido financiado ou apoiado/ The author has no support of funding to report. 
Conflito de interesses: $\mathrm{O}$ autor declara que não há conflito de interesse/ The author declares that has no conflict of interest

\section{Sergio Gomes da Silva}

Psicanalista em Formação pelo Círculo Brasileiro de Psicanálise - Seção Rio de Janeiro (Rio de Janeiro, RJ, Brasil); mestre em Saúde Coletiva pelo Instituto de Medicina Social da Universidade Estadual do Rio de Janeiro - UERJ (Rio de Janeiro, RJ, Brasil); especialista em Direitos Humanos pelo Departamento de Filosofia da Universidade Federal da Paraíba UFPB (João Pessoa, PB, Brasil); especialista em Sexualidade Humana pelo Centro de Educação da Universidade Federal da Paraíba - UFPB (João Pessoa, PB, Brasil).

Círculo Brasileiro de Psicanálise - Seção RJ

Av. Nossa Senhora de Copacabana, 769/504

22050-002 Rio de Janeiro, RJ, Brasil

e-mail: sergiogsilva@uol.com.br 